Check for updates

Cite this: RSC Adv., 2019, 9, 4789

Received 3rd December 2018 Accepted 21st January 2019

DOI: $10.1039 / \mathrm{c} 8 \mathrm{ra09947b}$

rsc.li/rsc-advances

\section{Analysis of energies of halogen and hydrogen bonding interactions in the solid state structures of vanadyl Schiff base complexes $\uparrow$}

\author{
Snehasish Thakur, ${ }^{a}$ Michael G. B. Drew, ${ }^{\mathrm{b}}$ Antonio Franconetti, (DD ${ }^{\mathrm{c}}$ \\ Antonio Frontera (D) ${ }^{* c}$ and Shouvik Chattopadhyay (D) *a
}

\begin{abstract}
Two mononuclear and two dinuclear vanadium(v) complexes, $\left[\mathrm{VO}_{2} \mathrm{~L}^{1}\right](1),\left[\mathrm{VO}_{2} \mathrm{~L}^{2}\right](2),(\mu-\mathrm{O})_{2}\left[\mathrm{~V}(\mathrm{O})\left(\mathrm{L}^{3}\right)\right]_{2}(3)$ and $(\mu-\mathrm{O})_{2}\left[\mathrm{~V}(\mathrm{O})\left(\mathrm{L}^{4}\right)\right]_{2} \cdot 2 \mathrm{H}_{2} \mathrm{O}(4)$, where $\mathrm{HL}^{1}=4$-bromo-6-[(2-phenylaminoethylimino)methyl]phenol, $\mathrm{HL}^{2}$ = 2-((2-(diethylamino)ethylimino)methyl)-4-chlorophenol, $\mathrm{HL}^{3}=2$-((2-(ethylamino)ethylimino)methyl)4-chlorophenol and $\mathrm{HL}^{4}=2$-(1-(2-(ethylamino)ethylimino)ethyl)phenol have been synthesized and characterized. Structures of all complexes have been confirmed by single crystal X-ray diffraction studies. Complexes 1, 2, and 3 exhibit significant halogen bonding interactions in their solid state structures. The energies associated to the supramolecular interactions have been explored using Density Functional Theory (DFT) calculations, and further confirmed with non-covalent interaction (NCl) plots.
\end{abstract}

\section{Introduction}

Supramolecular chemistry is enriched by the participation of carbon-bound halogen atoms (acting as electron acceptors), forming short contacts with both neutral and negatively charged species, having abilities to act as electron donors. ${ }^{1}$ This type of supramolecular interaction is commonly known as 'halogen bonding' to indicate their similarity with hydrogen bonding interactions. ${ }^{1 b, 1 e}$ These non-covalent interactions have been shown to have significant contribution in controlling the aggregation of different organic molecules in solid, ${ }^{2}$ liquid, ${ }^{3}$ and gases. ${ }^{4}$ Supramolecular chemists are very much interested in analyzing the nature of these halogen bonding interactions. ${ }^{5}$ Although hydrogen bonding interactions are the most frequently used means to assemble molecules in solid, liquid, and gas phases, and play important roles in stabilizing supramolecular aggregates even in water, ${ }^{6}$ the literature shows examples where 'halogen bonding' interactions may dominate over the hydrogen bonding interactions, depending upon the type of substituents and orientation of the responsible atoms with respect to the electron donor groups. ${ }^{7}$ However, there is no report in the literature regarding the analysis of halogen

${ }^{a}$ Department of Chemistry, Inorganic Section, Jadavpur University, Kolkata 700032 , India. E-mail: shouvik.chem@gmail.com

${ }^{b}$ School of Chemistry, The University of Reading, P. O. Box 224, Whiteknights, Reading RG6 6AD, UK

'Departament de Quimica, Universitat de les Illes Balears, Crta. De Valldemossa km 7.5, 07122 Palma, Baleares, Spain. E-mail: toni.frontera@uib.es

$\dagger$ Electronic supplementary information (ESI) available. CCDC 1879191-1879194 contain the supplementary crystallographic data for complexes 1-4 respectively. For ESI and crystallographic data in CIF or other electronic format see DOI: $10.1039 / \mathrm{c} 8 \mathrm{ra09947b}$ bonding interactions in the supramolecular systems generated by vanadyl Schiff base complex building blocks.

Recently, we have reported the synthesis and characterization of few vanadyl Schiff base complexes along with the analysis of supramolecular interactions in their solid state structures. ${ }^{8}$ Supramolecular interactions in those complexes were mainly governed by $\mathrm{C}-\mathrm{H} \cdots \pi, \pi \cdots \pi$ (chelate ring) and hydrogen bonding interactions. In the present work, we have designed the Schiff bases in such a way that supramolecular systems could be generated with the help of halogen bonding interactions along with conventional hydrogen bonding interactions. Four tridentate $\mathrm{N}_{2} \mathrm{O}$ donor Schiff bases, $\mathrm{HL}^{1}$ (4-bromo6-[(2-phenylaminoethylimino)methyl]phenol), $\quad \mathrm{HL}^{2} \quad 2-((2-$ (diethylamino)ethylimino)methyl)-4-chlorophenol, $\mathrm{HL}^{3} \quad 2-((2-$ (ethylamino)ethylimino)methyl)-4-chlorophenol and $\mathrm{HL}^{4}$ 2-(1(2-(ethylamino)ethylimino)ethyl)phenol have been used to prepare four complexes, $\left[\mathrm{VO}_{2} \mathrm{~L}^{1}\right] \quad(\mathbf{1}),\left[\mathrm{VO}_{2} \mathrm{~L}^{2}\right] \quad(2), \quad(\mu-$ $\mathrm{O})_{2}\left[\mathrm{~V}(\mathrm{O})\left(\mathrm{L}^{3}\right)\right]_{2}$ (3) and $(\mu-\mathrm{O})_{2}\left[\mathrm{~V}(\mathrm{O})\left(\mathrm{L}^{4}\right)\right]_{2} \cdot 2 \mathrm{H}_{2} \mathrm{O}$ (4). Significant halogen bonding interactions have been observed in the solid state structures of complexes $\mathbf{1 , 2}$ and $\mathbf{3}$. The energies involved in these interactions have been examined using DFT calculations, and further confirmed with NCI plots. The findings are impressive and hopefully encouraging for coordination as well as supramolecular chemists working in related areas.

\section{Experimental section}

VOSO $_{4} \cdot 5 \mathrm{H}_{2} \mathrm{O}$ was purchased from Loba Chemie Pvt. Ltd. and was of reagent grade. All other starting materials were commercially available, reagent grade, and used as purchased from Sigma-Aldrich without further purification. 


\subsection{Preparation}

2.1.1 Preparation of ligands, 4-bromo-6-[(2phenylaminoethylimino)methyl]phenol $\quad\left(\mathrm{HL}^{\mathbf{1}}\right), \quad 2-((2-$ (diethylamino)ethylimino)methyl)-4-chlorophenol ( $\left.\mathrm{HL}^{2}\right), 2-((2-$ (ethylamino)ethylimino)methyl)-4-chlorophenol $\left(\mathrm{HL}^{3}\right)$ and 2-(1(2-(ethylamino)ethylimino)ethyl)phenol $\left(\mathbf{H L}^{\mathbf{4}}\right)$. The tridentate Schiff base ligand, $\mathrm{HL}^{1}$, was prepared by refluxing 5 -bromosalicylaldehyde (201 mg, $1 \mathrm{mmol}$ ) with $N$-phenylethylenediamine (0.13 mL, $1 \mathrm{mmol})$ in $\mathrm{CH}_{3} \mathrm{CN}(10 \mathrm{~mL})$ for $c a .1 \mathrm{~h}$. $\mathrm{HL}^{2}$ was prepared in a similar method to that of $\mathrm{HL}^{1}$, except that $N, N$ diethylethylenediamine $(0.14 \mathrm{~mL}, 1 \mathrm{mmol})$ and 5-chlorosalicylaldehyde (156 mg, $1 \mathrm{mmol}$ ) were used instead of $\mathrm{N}$ phenylethylenediamine and 5-bromosalicylaldehyde, respectively. The tridentate ligands, $\mathrm{HL}^{3}$ and $\mathrm{HL}^{4}$, were synthesized by refluxing $N$-ethylethylenediamine $(0.11 \mathrm{~mL}, 1 \mathrm{mmol})$ with 5 chlorosalicylaldehyde (156 mg, $1 \mathrm{mmol})$ and 2'-hydroxyacetophenone $(136 \mathrm{mg}, 1 \mathrm{mmol})$, respectively in $\mathrm{CH}_{3} \mathrm{CN}$ (10 $\mathrm{mL}$ ) for $\mathrm{ca} .1 \mathrm{~h} 30 \mathrm{~min}$. All these ligands were not isolated and were directly used for the synthesis of their respective complexes.

2.1.2 Preparation of complexes $\left[\mathrm{VO}_{2} \mathrm{~L}^{1}\right](1),\left[\mathrm{VO}_{2} \mathrm{~L}^{2}\right](2),(\mu-$ $\mathbf{O})_{2}\left[\mathbf{V}(\mathbf{O})\left(\mathbf{L}^{3}\right)\right]_{2}(3)$ and $(\mu-\mathbf{O})_{2}\left[\mathbf{V}(\mathbf{O})\left(\mathbf{L}^{4}\right)\right]_{2} \cdot \mathbf{2} \mathbf{H}_{2} \mathbf{O}(\mathbf{4})$. All complexes were prepared in a general synthetic procedure. DMF or $\mathrm{CH}_{3} \mathrm{CN}$ $(10 \mathrm{~mL})$ solution of $\operatorname{VOSO}_{4} \cdot 5 \mathrm{H}_{2} \mathrm{O}(253 \mathrm{mg}, 1 \mathrm{mmol})$ was added to the $\mathrm{CH}_{3} \mathrm{CN}$ solution $(20 \mathrm{~mL})$ of the synthesized tridentate ligand and the resulting solution was then refluxed for $c a .3 \mathrm{~h}$. Subsequently, it was cooled to room temperature, filtered and kept for crystallization. Single crystals, suitable for X-ray diffraction, were obtained after 3-7 days on slow evaporation of the filtrate in open atmosphere.

[VO $\mathrm{VO}_{2} \mathrm{I}^{1}$ (1). Yield: $289 \mathrm{mg}(72 \%)$; anal. calc. for $\mathrm{C}_{15} \mathrm{H}_{14} \mathrm{BrN}_{2}$ $\mathrm{O}_{3} \mathrm{~V}(\mathrm{FW}=401.12) \mathrm{C}, 44.91 ; \mathrm{H}, 3.52 ; \mathrm{N}, 6.98 \%$. Found: $\mathrm{C}, 44.8$; $\mathrm{H}, 3.4$; N, 7.1\%; FT-IR (KBr, $\left.\mathrm{cm}^{-1}\right): 3077\left(\nu_{\mathrm{N}-\mathrm{H}}\right), 1630\left(\nu_{\mathrm{C}=\mathrm{N}}\right), 925$, 825 $\left(\nu_{\mathrm{V}=\mathrm{O}}\right)$, UV-Vis, $\lambda_{\max }(\mathrm{nm}),\left[\varepsilon_{\max }\left(\mathrm{L} \mathrm{mol}^{-1} \mathrm{~cm}^{-1}\right)\right]$ (DMF), 334 $\left(4.1 \times 10^{3}\right)$. Magnetic moment = diamagnetic.

[VO $\mathrm{VO}_{2}^{2}$ ] (2). Yield: $229 \mathrm{mg}(68 \%)$; anal. calc. for $\mathrm{C}_{13} \mathrm{H}_{18} \mathrm{ClN}_{2}-$ $\mathrm{O}_{3} \mathrm{~V}(\mathrm{FW}=336.68): \mathrm{C}, 46.37 ; \mathrm{H}, 5.39 ; \mathrm{N}, 8.32 \%$. Found: C, 46.3; $\mathrm{H}, 5.2 ; \mathrm{N}, 8.4 \%$; FT-IR $\left(\mathrm{KBr}, \mathrm{cm}^{-1}\right): 1627\left(\nu_{\mathrm{C}=\mathrm{N}}\right), 935,819\left(\nu_{\mathrm{V}=\mathrm{O}}\right)$, UV-Vis, $\lambda_{\max }(\mathrm{nm}),\left[\varepsilon_{\max }\left(\mathrm{L} \mathrm{mol}{ }^{-1} \mathrm{~cm}^{-1}\right)\right]\left(\mathrm{CH}_{3} \mathrm{CN}\right): 331(3.8 \times$ $\left.10^{3}\right)$. Magnetic moment $=$ diamagnetic.

$(\mu-O)_{2}\left[V(O)\left(L^{3}\right)\right]_{2}$ (3). Yield: $219 \mathrm{mg}$ (71\%); anal. calc. for $\mathrm{C}_{22^{-}}$ $\mathrm{H}_{28} \mathrm{Cl}_{2} \mathrm{~N}_{4} \mathrm{O}_{6} \mathrm{~V}_{2}(\mathrm{FW}=617.26): \mathrm{C}, 42.81 ; \mathrm{H}, 4.57 ; \mathrm{N}, 9.08 \%$; Found: C, 42.7; H, 4.4; N, 9.1\%; FT-IR $\left(\mathrm{KBr}, \mathrm{cm}^{-1}\right): 1641\left(\nu_{\mathrm{C}=\mathrm{N}}\right)$, 929, $836\left(\nu_{\mathrm{V}=\mathrm{O}}\right)$. UV-Vis, $\lambda_{\max }(\mathrm{nm}),\left[\varepsilon_{\max }\left(\mathrm{L} \mathrm{mol}^{-1} \mathrm{~cm}^{-1}\right)\right]$ $\left(\mathrm{CH}_{3} \mathrm{CN}\right): 382\left(6.8 \times 10^{3}\right)$. Magnetic moment = diamagnetic.

$(\mu-O)_{2}\left[V(O)\left(L^{4}\right)\right]_{2} \cdot 2 \mathrm{H}_{2} \mathrm{O}(4)$. Yield: $211 \mathrm{mg}(69 \%)$; anal. calc. for $\mathrm{C}_{24} \mathrm{H}_{38} \mathrm{~N}_{4} \mathrm{O}_{8} \mathrm{~V}_{2}(\mathrm{FW}=612.46): \mathrm{C}, 47.07 ; \mathrm{H}, 6.25 ; \mathrm{N}, 9.15 \%$; Found: C, 47.0; H, 6.1; N, 9.2\%; FT-IR $\left(\mathrm{KBr}, \mathrm{cm}^{-1}\right): 3212\left(\nu_{\mathrm{N}-\mathrm{H}}\right)$, $1606\left(\nu_{\mathrm{C}=\mathrm{N}}\right), 930\left(\nu_{\mathrm{V}=\mathrm{O}}\right) .464\left(\nu_{\mathrm{V}-\mathrm{O}}\right), \mathrm{UV}-\mathrm{Vis}, \lambda_{\max }(\mathrm{nm}),\left[\varepsilon_{\max }(\mathrm{L}\right.$ $\left.\left.\mathrm{mol}^{-1} \mathrm{~cm}^{-1}\right)\right]\left(\mathrm{CH}_{3} \mathrm{CN}\right): 352\left(7.0 \times 10^{3}\right)$. Magnetic moment $=$ diamagnetic.

\subsection{Physical measurements}

Elemental analyses (carbon, hydrogen and nitrogen) were performed using a Perkin Elmer 240C elemental analyzer. IR spectra in $\mathrm{KBr}\left(4500-500 \mathrm{~cm}^{-1}\right)$ were recorded with a Perkin
Elmer Spectrum Two spectrophotometer. Electronic spectrum of complex 1 (in DMF) and that of complexes 2-4 (in $\mathrm{CH}_{3} \mathrm{CN}$ ) were recorded on a Shimadzu UV-1700 UV-Vis spectrophotometer. The magnetic susceptibility measurements were performed with an EG and PAR vibrating sample magnetometer, model 155 at room temperature $(300 \mathrm{~K})$ in a $5000 \mathrm{G}$ magnetic field, and diamagnetic corrections were performed using Pascal's constants.

\subsection{X-ray crystallography}

For each complex, a suitable single crystal was picked and mounted on a glass fiber, and diffraction intensities were measured with an Oxford Diffraction X-Calibur diffractometer, equipped with Mo $\mathrm{K}_{\alpha}$ radiation $(\lambda=0.71073 \AA$, $50 \mathrm{kV}, 40 \mathrm{~mA})$ at temperature $150 \mathrm{~K}$. Data collection and reduction were performed with the Oxford Diffraction Crystalis system. Structures of the complexes were solved by direct method and refined by full-matrix least squares on $F^{2}$, using the SHELX-2016/6 package. ${ }^{9}$ The absorption correction type is empirical with ABSPACK program of Oxford Diffraction Ltd. Non-hydrogen atoms were refined anisotropically. Hydrogen atoms attached to nitrogen and oxygen atoms were located by difference Fourier maps. All other hydrogen atoms were placed in their geometrically idealized positions and constrained to ride on their parent atoms. Programs used: SHELX-2016/6, ${ }^{9}$ PLATON, ${ }^{10}$ WINGX, ${ }^{11}$ ORTEP, ${ }^{12}$ and MERCURY. ${ }^{13}$ Significant crystallographic data are summarized in Table 1 . Selected bond lengths and bond angles are gathered in Tables 2 and 3, respectively.

\subsection{Theoretical methods}

The geometries of the complexes included in this study were computed at the M06-2X/def2-TZVP level of theory using the crystallographic coordinates. Therefore, the interaction energies were calculated using the frozen monomers as they are in the dimers. For all calculations, the GAUSSIAN-09 program has been used. ${ }^{14}$ The Grimme's dispersion correction ${ }^{15}$ has also been used as implemented in GAUSSIAN-09 program since it is adequate for the evaluation of non-covalent interactions where dispersion effects are relevant like $\sigma$-hole interactions. The basis set superposition error for the calculation of interaction energies has been corrected using the counterpoise method. ${ }^{\mathbf{1 6}}$ The NCI plot $^{17}$ isosurfaces have been used to characterize noncovalent interactions. They correspond to both favorable and unfavorable interactions, as differentiated by the sign of the second density Hessian eigenvalue and defined by the isosurface color. The color scheme is a red-yellow-green-blue scale with red for $\rho_{\text {cut }}{ }^{+}$(repulsive) and blue for $\rho_{\text {cut }}{ }^{-}$(attractive). Molecular Electrostatic Potential surfaces have been computed at the M06-2X/6-31+G* level using the SPARTAN'10 program version 1.1.0. The SAPT (symmetry adapted perturbation theory ${ }^{18}$ has been used to decompose the interaction energy into well-defined components (electrostatic, exchange, induction, and dispersion terms). The DFT-SAPT calculations have been performed using the PBE0/def2-TZVP level of theory and the MOLPRO program. ${ }^{19}$ 
Table 1 Crystal data and refinement details of complexes 1-4

\begin{tabular}{|c|c|c|c|c|}
\hline Complex & 1 & 2 & 3 & 4 \\
\hline Formula & $\mathrm{C}_{15} \mathrm{H}_{14} \mathrm{BrN}_{2} \mathrm{O}_{3} \mathrm{~V}$ & $\mathrm{C}_{13} \mathrm{H}_{18} \mathrm{ClN}_{2} \mathrm{O}_{3} \mathrm{~V}$ & $\mathrm{C}_{22} \mathrm{H}_{28} \mathrm{Cl}_{2} \mathrm{~N}_{4} \mathrm{O}_{6} \mathrm{~V}_{2}$ & $\mathrm{C}_{24} \mathrm{H}_{38} \mathrm{~N}_{4} \mathrm{O}_{8} \mathrm{~V}_{2}$ \\
\hline Formula weight & 401.12 & 336.68 & 617.26 & 612.46 \\
\hline Crystal system & Monoclinic & Monoclinic & Monoclinic & Monoclinic \\
\hline Space group & $P c$ & $P 2_{1} / n$ & $I 2 / a$ & $P 2_{1} / n$ \\
\hline$a(\AA)$ & $12.7168(14)$ & $14.1152(7)$ & $22.194(2)$ & $8.9266(4)$ \\
\hline$\alpha(\mathrm{deg})$ & 90 & 90 & 90 & 90 \\
\hline$\beta$ (deg) & $91.74(1)$ & $106.842(5)$ & $97.479(10)$ & $96.547(4)$ \\
\hline$\gamma(\mathrm{deg})$ & 90 & 90 & 90 & 90 \\
\hline$Z$ & 2 & 4 & 4 & 2 \\
\hline$d_{\text {calc }}\left(\mathrm{g} \mathrm{cm}^{-3}\right)$ & 1.754 & 1.576 & 1.583 & 1.500 \\
\hline$\mu\left(\mathrm{mm}^{-1}\right)$ & 3.297 & 0.895 & 0.973 & 0.743 \\
\hline No. of parameters & 199 & 183 & 167 & 182 \\
\hline$R_{\text {(int) }}$ & 0.053 & 0.030 & 0.030 & 0.035 \\
\hline$R_{1}, \mathrm{w} R_{2}$ (all data) & $0.0693,0.1446$ & $0.0464,0.0947$ & $0.0595,0.1075$ & $0.0604,0.1072$ \\
\hline$R_{1}, \mathrm{w} R_{2}[I>2 \sigma(I)]$ & $0.0609,0.1345$ & $0.0377,0.0911$ & $0.0443,0.1015$ & $0.0476,0.1091$ \\
\hline
\end{tabular}

\section{Results and discussions}

\subsection{Synthesis}

Four Schiff bases, $\mathrm{HL}^{1}, \mathrm{HL}^{2}, \mathrm{HL}^{3}$ and $\mathrm{HL}^{4}$, have been prepared by the condensation of appropriate diamines and salicylaldehyde derivatives in $\mathrm{CH}_{3} \mathrm{CN}$, following the literature methods. ${ }^{20}$ The ligands were not isolated and were reacted with $\mathrm{VOSO}_{4}{ }^{-}$ $\cdot 5 \mathrm{H}_{2} \mathrm{O}$ (dissolved either in DMF or $\mathrm{CH}_{3} \mathrm{CN}$ ) in open atmosphere to synthesize two mononuclear vanadium(v) complexes, $\left[\mathrm{VO}_{2} \mathrm{~L}^{1}\right]$ (1) and $\left[\mathrm{VO}_{2} \mathrm{~L}^{2}\right]$ (2) and two dinuclear vanadium(v) complexes, $(\mu-\mathrm{O})_{2}\left[\mathrm{~V}(\mathrm{O})\left(\mathrm{L}^{3}\right)\right]_{2}(3)$ and $(\mu-\mathrm{O})_{2}\left[\mathrm{~V}(\mathrm{O})\left(\mathrm{L}^{4}\right)\right]_{2} \cdot 2 \mathrm{H}_{2} \mathrm{O}(4)$, where $\mathrm{L}^{1}, \mathrm{~L}^{2}$, $\mathrm{L}^{3}$ and $\mathrm{L}^{4}$ are the deprotonated mono-anionic forms of the respective Schiff bases. The effort to prepare these complexes under $\mathrm{N}_{2}$ environment was unsuccessful. This is because all the syntheses involves the oxidation of vanadium from +4 (in starting material) to +5 (in complexes 1-4). The oxidation of vanadium centers may therefore be caused by aerial oxygen. Synthetic route to the complexes is outlined in Scheme 1.

\subsection{Description of structures}

3.2.1 $\left[\mathrm{VO}_{2} \mathrm{~L}^{1}\right]$ (1) and $\left[\mathrm{VO}_{2} \mathrm{~L}^{2}\right]$ (2). A perspective view of complex $\mathbf{1}$ with the selective atom numbering scheme is shown

Table 2 Selected bond lengths $(\AA)$ for complexes $1-4^{a}$

\begin{tabular}{lllll}
\hline Complex & 1 & 2 & 3 & 4 \\
\hline $\mathrm{V}(1)-\mathrm{O}(1)$ & $1.628(7)$ & $1.6228(13)$ & $1.6159(14)$ & $1.6812(15)$ \\
$\mathrm{V}(1)-\mathrm{O}(2)$ & $1.625(8)$ & $1.6215(14)$ & $1.6773(15)$ & $1.6100(15)$ \\
$\mathrm{V}(1)-\mathrm{O}(11)$ & $1.903(8)$ & $1.9160(13)$ & $1.9150(15)$ & $1.9033(16)$ \\
$\mathrm{V}(1)-\mathrm{N}(19)$ & $2.118(8)$ & $2.1424(14)$ & $2.1637(17)$ & $2.1703(18)$ \\
$\mathrm{V}(1)-\mathrm{N}(22)$ & $2.159(9)$ & $2.2021(14)$ & $2.1554(18)$ & $2.1300(18)$ \\
$\mathrm{V}(1)-\mathrm{O}\left(2^{\mathrm{a}}\right)$ & - & - & $2.3096(15)$ & - \\
$\mathrm{V}(1)-\mathrm{O}\left(1^{\mathrm{b}}\right)$ & - & - & - & $2.4008(15)$
\end{tabular}

${ }^{a}$ Symmetry transformations: $\mathrm{a}=1-x, 2-y,-z, \mathrm{~b}=-x, 1-y,-z$. in Fig. 1. Complex 2 has a very similar structure (Fig. S1, ESI†). The vanadium(v) center is five coordinated in each complex. The basal plane in each complex is composed of one imine nitrogen atom, $\mathrm{N}(19)$, one amine nitrogen atom, $\mathrm{N}(22)$, one phenoxo oxygen atom, $\mathrm{O}(11)$, of a deprotonated Schiff base ligand and an oxo group [O(1) for $\mathbf{1}$ and $\mathrm{O}(2)$ for 2]. The apical positions are occupied by a second oxo group, i.e. $\mathrm{O}(2)$ for $\mathbf{1}$ and $\mathrm{O}(1)$ for 2 . The geometry of any penta-coordinated metal center is generally measured by the Addison parameter $(\tau)[\tau=(\alpha-\beta) /$ 60 , where $\alpha$ and $\beta$ are the two largest ligand-metal-ligand angles in the coordination sphere $(\tau=0$ infers an ideal square

Table 3 Selected bond angles $\left(^{\circ}\right)$ for complexes $1-4^{a}$

\begin{tabular}{lllll}
\hline Complex & 1 & 2 & 3 & 4 \\
\hline $\mathrm{O}(1)-\mathrm{V}(1)-\mathrm{O}(2)$ & $110.4(4)$ & $110.67(7)$ & $106.99(7)$ & $107.49(7)$ \\
$\mathrm{O}(1)-\mathrm{V}(1)-\mathrm{O}(11)$ & $96.1(3)$ & $102.95(6)$ & $101.45(7)$ & $97.02(7)$ \\
$\mathrm{O}(1)-\mathrm{V}(1)-\mathrm{N}(19)$ & $137.4(4)$ & $113.96(6)$ & $97.03(7)$ & $152.91(7)$ \\
$\mathrm{O}(1)-\mathrm{V}(1)-\mathrm{N}(22)$ & $90.1(3)$ & $93.96(6)$ & $91.50(7)$ & $92.46(7)$ \\
$\mathrm{O}(2)-\mathrm{V}(1)-\mathrm{O}(11)$ & $102.8(4)$ & $96.96(6)$ & $99.22(7)$ & $102.64(7)$ \\
$\mathrm{O}(2)-\mathrm{V}(1)-\mathrm{N}(19)$ & $111.1(3)$ & $134.29(6)$ & $154.28(7)$ & $98.56(7)$ \\
$\mathrm{O}(2)-\mathrm{V}(1)-\mathrm{N}(22)$ & $96.0(4)$ & $90.68(6)$ & $92.65(7)$ & $93.06(7)$ \\
$\mathrm{O}(11)-\mathrm{V}(1)-\mathrm{N}(19)$ & $83.8(3)$ & $82.50(5)$ & $84.56(7)$ & $84.16(6)$ \\
$\mathrm{O}(11)-\mathrm{V}(1)-\mathrm{N}(22)$ & $156.7(3)$ & $157.52(5)$ & $158.96(6)$ & $158.22(6)$ \\
$\mathrm{N}(19)-\mathrm{V}(1)-\mathrm{N}(22)$ & $76.6(3)$ & $77.09(5)$ & $77.38(6)$ & $78.58(6)$ \\
$\mathrm{O}(1)-\mathrm{V}(1)-\mathrm{O}\left(1^{\mathrm{b}}\right)$ & - & - & - & $77.94(6)$ \\
$\mathrm{O}\left(1^{\mathrm{b}}\right)-\mathrm{V}(1)-\mathrm{O}(2)$ & - & - & - & $170.29(7)$ \\
$\mathrm{O}\left(1^{\mathrm{b}}\right)-\mathrm{V}(1)-\mathrm{O}(11)$ & - & - & - & $84.36(6)$ \\
$\mathrm{O}\left(1^{\mathrm{b}}\right)-\mathrm{V}(1)-\mathrm{N}(19)$ & - & - & - & $75.24(5)$ \\
$\mathrm{O}\left(1^{\mathrm{b}}\right)-\mathrm{V}(1)-\mathrm{N}(22)$ & - & - & - & $78.49(6)$ \\
$\mathrm{O}(1)-\mathrm{V}(1)-\mathrm{O}\left(2^{\mathrm{a}}\right)$ & - & - & $169.79(7)$ & - \\
$\mathrm{O}(2)-\mathrm{V}(1)-\mathrm{O}\left(2^{\mathrm{a}}\right)$ & - & - & $78.78(6)$ & - \\
$\mathrm{O}\left(2^{\mathrm{a}}\right)-\mathrm{V}(1)-\mathrm{O}(11)$ & - & - & $85.63(6)$ & - \\
$\mathrm{O}\left(2^{\mathrm{a}}\right)-\mathrm{V}(1)-\mathrm{N}(19)$ & - & - & $76.15(6)$ & - \\
$\mathrm{O}\left(2^{\mathrm{a}}\right)-\mathrm{V}(1)-\mathrm{N}(22)$ & - & - & $79.68(6)$ & -
\end{tabular}




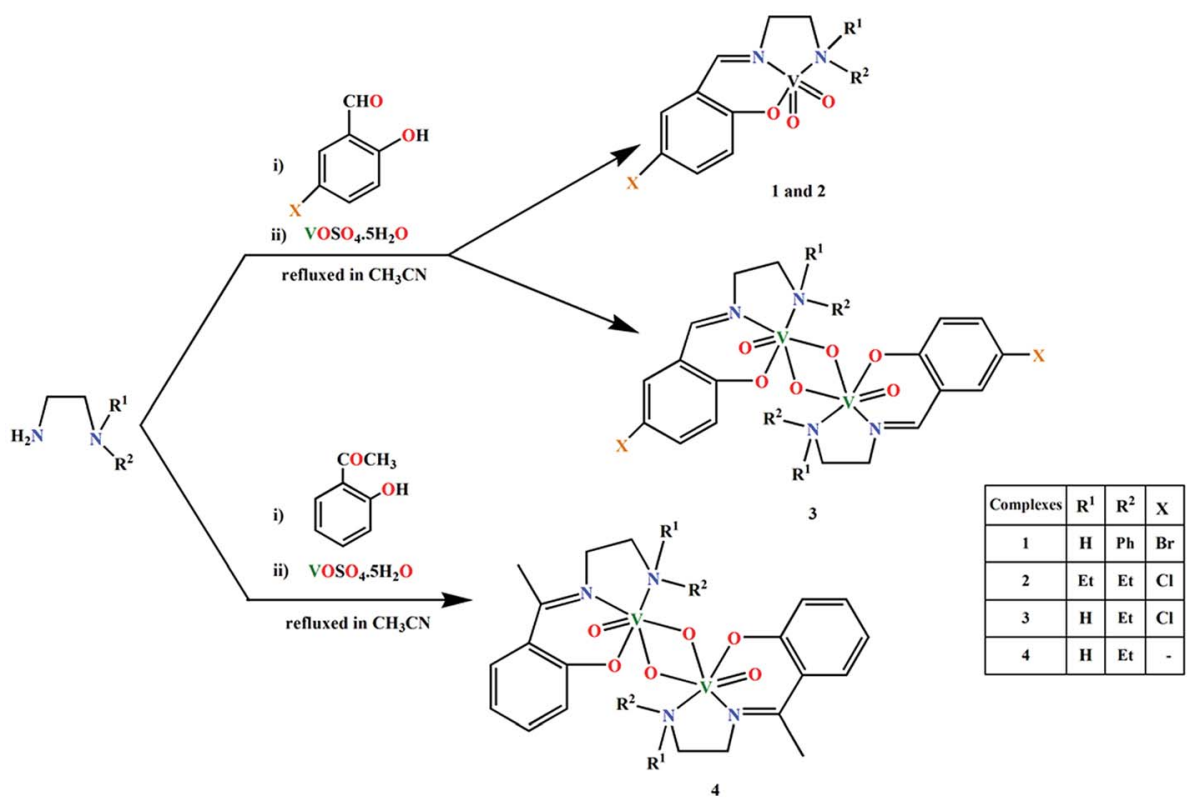

Scheme 1 Synthetic route to complexes 1-4.

pyramid and $\tau=1$ infers a perfect trigonal bipyramid)]. ${ }^{21}$ The $\tau$ value is found to be $\sim 0.3$ in each complex, indicating a severely distorted square pyramidal geometry around the vanadium(v) centers. ${ }^{22}$ In 1, the coordinating atoms, N(19), N(22), O(11), and $\mathrm{O}(1)$, deviate from the mean plane passing through them by $-0.171(4) \AA, 0.170(4) \AA, 0.172(4) \AA,-0.171(4) \AA$ with the metal $0.487(5) \AA$ from the plane in the direction of terminal $\mathrm{O}(2)$. In 2 , the geometry is slightly more distorted. With $\mathrm{O}(1)$ chosen as the axial atom, the deviations for $\mathrm{N}(19), \mathrm{N}(22), \mathrm{O}(11), \mathrm{O}(2)$ are $0.2147(7) \AA,-0.2086(7) \AA,-0.2183(8) \AA, 0.2131(8) \AA$ with the metal $0.4925(8) \AA$ from the plane in the direction of $\mathrm{O}(1)$. The $\mathrm{V}(1)-\mathrm{O}(1)$ and $\mathrm{V}(1)-\mathrm{O}(2)$ distances are $\sim 1.62 \AA$ in both complexes, as expected for typical $\mathrm{V}=\mathrm{O}$ double bonds. ${ }^{23}$ The bond distances and angles in both complexes are similar to those observed in analogous vanadium(v) complexes with Schiff bases. ${ }^{24}$ Saturated five membered chelate ring, V(1)-N(19)$\mathrm{C}(20)-\mathrm{C}(21)-\mathrm{N}(22)$, assumes a half-chair conformation with puckering parameters $q=0.411(12) \AA$ and $\varphi=282.1(11)^{\circ}$ in complex 1, and an envelope conformation with puckering parameters $q=0.4482(17) \AA$ and $\varphi=104.78(17)^{\circ}$ in complex 2 .

3.2.2 $(\mu-\mathrm{O})_{2}\left[\mathrm{~V}(\mathrm{O})\left(\mathrm{L}^{3}\right)\right]_{2}(3)$ and $(\mu-\mathrm{O})_{2}\left[\mathrm{~V}(\mathrm{O})\left(\mathrm{L}^{4}\right)\right]_{2} \cdot 2 \mathrm{H}_{2} \mathrm{O}(4)$. Both complexes 3 (Fig. 2) and 4 (Fig. S2, ESI $\dagger$ ) are double oxobridged centrosymmetric dimers containing $\mathrm{V}_{2} \mathrm{O}_{2}$ cores. Vana$\operatorname{dium}(\mathrm{v})$ centers in them are six coordinate and distorted octahedral. The crystallographic asymmetric unit in each complex consists of one vanadium atom, $\mathrm{V}(1)$, two oxo groups, $\mathrm{O}(1)$ and $\mathrm{O}(2)$, and one tridentate (deprotonated) Schiff base ligand binding to the vanadium(v) center via imine nitrogen atom, $\mathrm{N}(19)$, amine nitrogen atom, $\mathrm{N}(22)$, and the phenolate oxygen atom, $\mathrm{O}(11)$. The asymmetric unit of complex 4 contains a lattice water molecule. The equatorial plane is defined with phenolic oxygen atom, $\mathrm{O}(11)$, imine nitrogen atom, $\mathrm{N}(19)$, and an amine nitrogen atom, $\mathrm{N}(22)$, of the Schiff base ligand and one oxo oxygen atom, $\mathrm{O}(2)$ for complex 3 and $\mathrm{O}(1)$ for complex 4 , respectively. Two axial positions are occupied by two oxo oxygen atoms; $\mathrm{O}(1), \mathrm{O}\left(2^{\mathrm{a}}\right)[\mathrm{a}=1-x, 2-y,-z]($ for complex 3$)$ and $\mathrm{O}\left(1^{\mathrm{b}}\right)$ $[\mathrm{b}=-x, 1-y,-z], \mathrm{O}(2)$ (for complex 4). In the $\mathrm{V}_{2} \mathrm{O}_{2}$ core of each dimer, one vanadium(v)-oxygen distance is shorter $[\mathrm{V}(1)-\mathrm{O}(2)=$ 1.681(1) ̊̊ for complex 3, V(1)-O(1) = 1.677(1) A for complex 4]

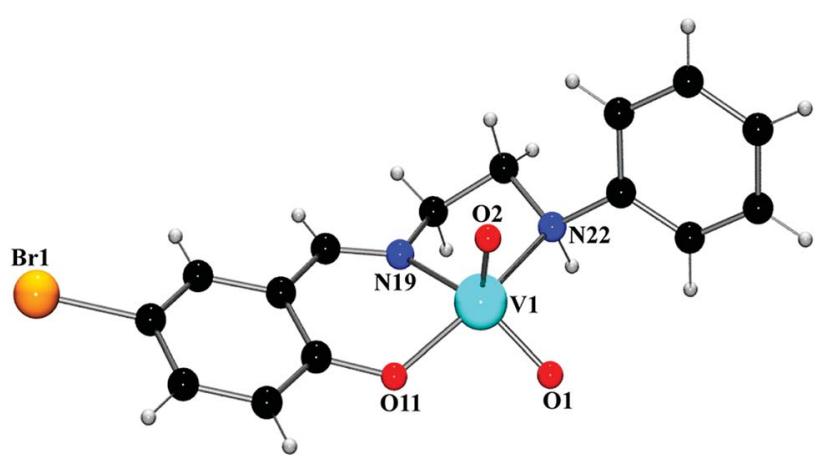

Fig. 1 Perspective view of complex 1 with selective atom numbering scheme.

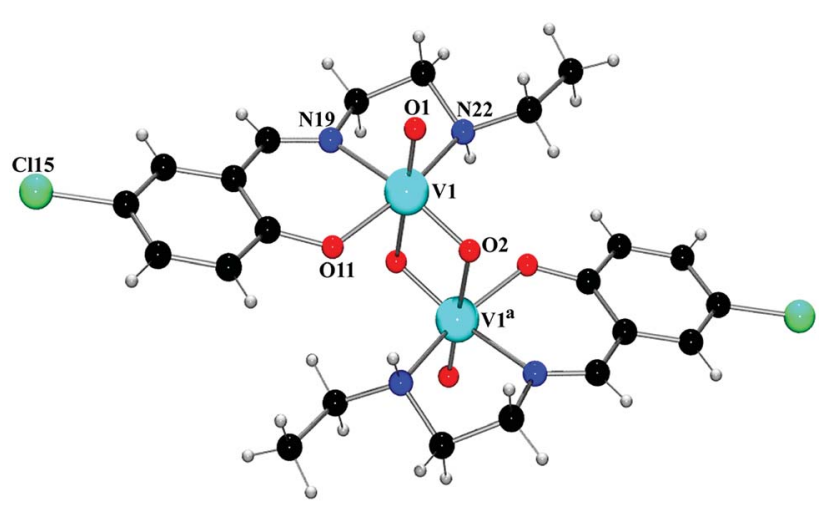

Fig. 2 Perspective view of complex 3 with selective atom numbering scheme. Symmetry transformation: $a=1-x, 2-y,-z$. 
compared to the other vanadium(v)-oxygen distance $\left[\mathrm{V}(1)-\mathrm{O}\left(2^{\mathrm{a}}\right)\right.$ $=2.401(1) \AA$ for complex $3, \mathrm{~V}(1)-\mathrm{O}\left(1^{\mathrm{b}}\right)=2.310(1) \AA$ for complex 4]. The short vanadium-oxygen distance corresponds to a $\mathrm{V}=\mathrm{O}$ double bond. ${ }^{25}$ The $\mathrm{V}-\mathrm{O}$ and $\mathrm{V}-\mathrm{N}$ bond lengths in the complexes are comparable to the corresponding values observed in other similar oxovanadium(v) complexes with Schiff bases. ${ }^{24 a, 26}$ The chelating angles, $\mathrm{N}(19)-\mathrm{V}(1)-\mathrm{N}(22)$ and $\mathrm{N}(19)-\mathrm{V}(1)-\mathrm{O}(22)$ have the values in the range $78-84^{\circ}$, indicating distortion of the octahedron around vanadium(v) centers. ${ }^{27}$ The intramolecular $\mathrm{V} \cdot \cdots \mathrm{V}$ separations are 3.107(5) $\AA$ (complex 3) and 3.206(5) $\AA$ (complex 4), which fall within the range of known $\mathrm{V} \cdots \mathrm{V}$ distances in double-bridged vanadium polynuclear systems. ${ }^{28}$ Depending on the orientation of $\mathrm{V}=\mathrm{O}$ groups with respect to the plane through two vanadium centers and two bridging oxogroups, the $\left\{\mathrm{V}_{2} \mathrm{O}_{4}\right\}^{2+}$ core can have five different configurations (syn and anti-orthogonal, syn- and anti-coplanar, twist) in complexes constructed from two $c i s-\mathrm{VO}^{2+}$ (pervanadyl) units. ${ }^{29}$ Both these complexes may be termed as anti-coplanar, as the two terminal $\mathrm{V}=\mathrm{O}$ bonds in both complexes are oriented in an anti arrangement with respect to the $\left\{\mathrm{V}_{2} \mathrm{O}_{2}\right\}$ plane. The coordination environment may then be best described as two edgeshared vanadium octahedra that are significantly distorted. The assignment of the +5 oxidation state for the vanadium centers in both complexes is confirmed by the bond valence sum calculations, ${ }^{30}$ which give 4.946 and 4.943 valence units for vanadium centers in complexes 3 and $\mathbf{4}$, respectively.

\subsection{Theoretical studies on supramolecular interactions in complexes 1,2 and 3}

Four new Schiff base complexes of $\mathrm{VO}_{2}{ }^{+}$have been synthesized and characterized by X-ray crystallography. Some of them contain halogen atoms in the structure $(\mathrm{Br}$ or $\mathrm{Cl})$, that participate in halogen bonding or hydrogen bonding interactions. The theoretical study is devoted to analyze the energy associated to the halogen bonding or hydrogen bonding interactions involving the halogen atoms in complexes 1, 2 and 3.

In Fig. 3a, a partial view of the X-ray structure of $\mathbf{1}$ is presented, where an infinite supramolecular chain is formed that is governed by the formation of $\mathrm{Br} \cdots \pi$ interactions and where the $\pi$-system corresponds to a $\mathrm{C}=\mathrm{C}$ bond of the aromatic ring. First of all, the molecular electrostatic potential (MEP) surface in complex 1 has been computed and it reveals an anisotropic distribution around the $\mathrm{Br}$ atom (it is represented only for the $\mathrm{Br}$ atom in Fig. 3a, right). The MEP value at the $\sigma$-hole of $\mathrm{Br}$ is $+8 \mathrm{kcal} \mathrm{mol}^{-1}$ and at the belt is $-15 \mathrm{kcal} \mathrm{mol}^{-1}$. A dimer, retrieved from the infinite chain, has been computed and the formation energy is moderately strong, $\Delta E_{1}=-4.3 \mathrm{kcal} \mathrm{mol}^{-1}$. The DFT-SAPT computed for this dimer shows that the interaction is dominated by induction and dispersion effects that represent the $75 \%$ of the sum of the attractive terms followed by the electrostatic term. The 'non-covalent interaction plot' (NCI plot) index has also been computed in order to characterize the $\mathrm{Br} \cdots \pi$ interaction in the dimer of $\mathbf{1}$. The NCI plot is an intuitive visualization index that enables the identification of noncovalent interactions easily and efficiently. This plot is convenient to analyze host-guest interactions since it clearly shows which molecular regions interact. The colour scheme is a redyellow-green-blue scale with red (repulsive) and blue (attractive). Yellow and green surfaces correspond to weak repulsive and weak attractive interactions, respectively. The representation of the NCI plot is shown in Fig. 3c. As noted, the halogen bond is characterized by a green isosurface that covers the aromatic $\mathrm{C}=\mathrm{C}$ bond and thus confirming the existence of the $\mathrm{Br} \cdots \pi$ interaction.

A partial view of the X-ray structure of 2 is given in Fig. $4 a$, where an infinite one dimensional supramolecular chain is represented. In this supramolecular assembly, the halogen bonding is established between the $\mathrm{Cl}$ atom and one $\mathrm{O}$ atom of the $\mathrm{VO}_{2}{ }^{+}$moiety, which is a better electron donor compared to the $\pi$-system. The MEP surface of complex 2 also shows an anisotropic distribution around the $\mathrm{Cl}$ atom; however, the MEP value at the $\sigma$-hole of $\mathrm{Cl}$ is very small, i.e. $+2 \mathrm{kcal} \mathrm{mol}^{-1}$ and at the belt is $-17 \mathrm{kcal} \mathrm{mol}^{-1}$. A dimer, retrieved from the infinite chain, has been computed and the formation energy is similar to that computed above for complex $1\left(\Delta E_{2}=-4.6 \mathrm{kcal} \mathrm{mol}^{-1}\right.$, Fig. 4 b), which is likely due to a compensating effect (worse $\sigma$ hole donor and better $\sigma$-hole acceptor compared to complex 1). The DFT-SAPT in this case shows that the interaction is dominated by electrostatic effects that represent the $55 \%$ of the sum of the attractive terms followed by the induction and dispersion terms (45\%). The NCI plot index has also been calculated in order to characterize the halogen bonding interaction in the dimer of 2 (Fig. 4c). The halogen bond is characterized by a small green isosurface that is located between the $\mathrm{Cl}$ and $\mathrm{O}$

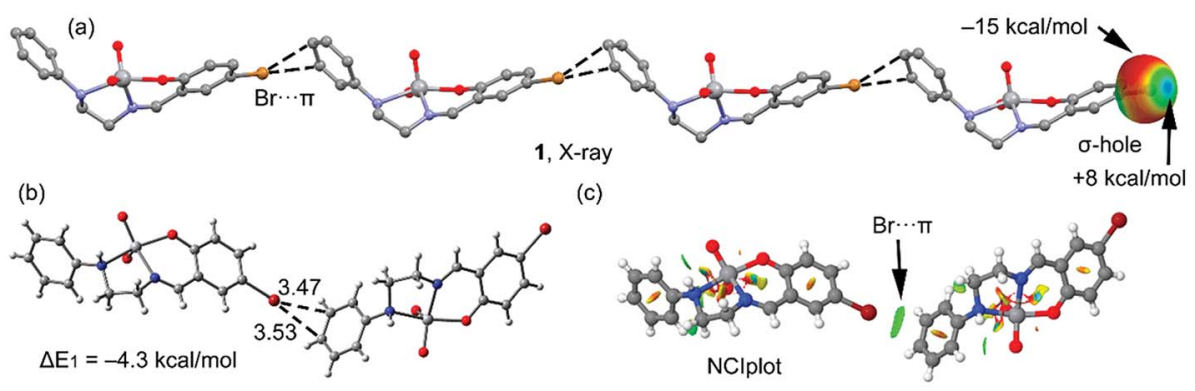

Fig. 3 (a) One dimensional supramolecular chain observed in the X-ray solid state structure of 1 and the MEP surface (isodensity $=0.001$ a.u.) around the $\mathrm{Br}$ atom. Hydrogen atoms have been omitted for clarity. (b) Theoretical model used to evaluate the interaction energy. (c) $\mathrm{NCl}$ surface of the dimer of complex 1 . The gradient cut-off is $s=0.35$ a.u., and the colour scale is $-0.04<\rho<0.04$ a.u. 


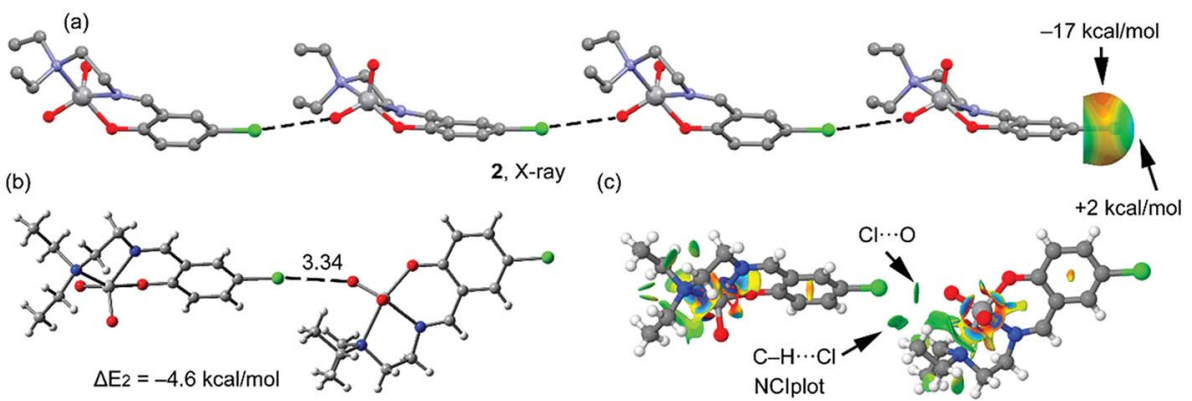

Fig. 4 (a) One dimensional supramolecular chain observed in the X-ray solid state structure of 2 and the MEP surface (isodensity $=0.001$ a.u.) around the $\mathrm{Cl}$ atom. Hydrogen atoms have been omitted for clarity. (b) Dimer retrieved from the crystal structure of complex 2 . Distances in $\AA$. (c) $\mathrm{NCl}$ surface of the dimer of complex 2. The gradient cut-off is $s=0.35$ a.u., and the color scale is $-0.04<\rho<0.04$ a.u.
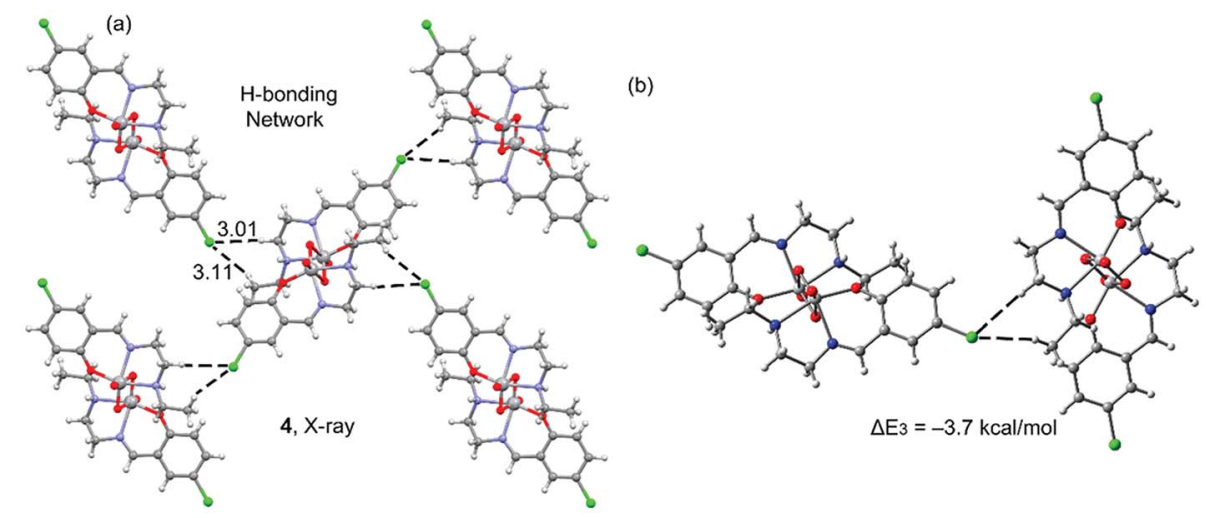

Fig. 5 Partial view of the X-ray solid state structure of 3 (a) and the theoretical model (b). Distances in $\AA$.

atoms. Moreover, an additional green isosurface is located between the aliphatic hydrogen atoms of one methyl group and the negative belt at the $\mathrm{Cl}$ atoms, thus also contributing to the stabilization of the dimer and also explaining the larger binding energy obtained for $\mathbf{2}$ compared to $\mathbf{1}$.

Complex 3 also has a chlorine atom as substituent; however, it does not participate in halogen bonding interactions. Instead, it establishes several $\mathrm{C}-\mathrm{H} \cdots \mathrm{Cl}$ interactions. In fact, its solid state structure (Fig. 5a) shows that each dinuclear complex establishes four sets of $\mathrm{C}-\mathrm{H} \cdots \mathrm{Cl}$ interactions: two as donor and two as acceptors, generating a two dimensional sheet. The interaction energy of the hydrogen bonded dimer is modest, $\Delta E_{3}=-3.7 \mathrm{kcal} \mathrm{mol}^{-1}$ and smaller than the halogen bonding computed for 1 and 2 , thus suggesting that the halogen bond is favoured in these vanadium systems. The DFT-SAPT computed for this interaction shows that it is dominated by electrostatic effects that represent the $75 \%$ of the sum of the attractive terms.

\subsection{IR, electronic spectra and magnetic moments}

Strong and sharp bands due to azomethine $(\mathrm{C}=\mathrm{N})$ groups in the range $1600-1640 \mathrm{~cm}^{-1}$ have been customarily noticed in the IR spectra of these complexes. ${ }^{31}$ Strong bands around $930 \mathrm{~cm}^{-1}$ and $825 \mathrm{~cm}^{-1}$ in all complexes may be assigned to asymmetric and symmetric $\nu_{(\mathrm{O}=\mathrm{V}=\mathrm{O})}$ vibrations of cis $-\mathrm{VO}_{2}$ groups present. ${ }^{32}$ The $\nu_{(\mathrm{V}-\mathrm{O})}$ bands can be monitored around $460 \mathrm{~cm}^{-1}$ for all complexes. ${ }^{33}$ These values are in good agreement with similar vanadium(v) Schiff base complexes. Sharp bands around $3310 \mathrm{~cm}^{-1}$ may be assigned to $\nu_{(\mathrm{N}-\mathrm{H})}$ stretching vibrations in complexes 3 and $4 .{ }^{34}$ Bands in the range of $2998-2806 \mathrm{~cm}^{-1}$ due to alkyl $\mathrm{C}-\mathrm{H}$ bond stretching vibrations are customarily noticed in the IR spectra of all the complexes. ${ }^{35}$

Electronic spectrum of each complex shows an absorption band around $350 \mathrm{~nm}$. This band may be assigned as a ligand-tometal charge transfer (LMCT) transition, originating from the $\mathrm{p}_{\pi}$ orbital on the phenolate oxygen to the empty d orbitals of the vanadium(v). ${ }^{36}$ As all these vanadium(v) complexes has a $3 \mathrm{~d}^{0}$ configuration, $\mathrm{d}-\mathrm{d}$ bands are not expected to appear in their electronic spectra. ${ }^{37}$

All these complexes are diamagnetic as expected for mononuclear and dinuclear vanadium(v) complexes with $\mathrm{d}^{0}$ configuration, as also observed for other similar vanadium(v) complexes. $^{38}$

\section{Conclusion}

Four new $\mathrm{VO}_{2}{ }^{+}$complexes with Schiff base ligands have been prepared and structurally characterized. Supramolecular interactions were investigated in details. An infinite one dimensional supramolecular chain is formed in complex $\mathbf{1}$, governed by the formation of $\mathrm{Br} \cdots \pi$ interactions (where the $\pi$-system corresponds to a $\mathrm{C}=\mathrm{C}$ bond of the aromatic ring). A dimer, retrieved from the infinite chain, has been computed and the formation energy is moderately strong, $\Delta E_{1}=-4.3 \mathrm{kcal} \mathrm{mol}^{-1}$. 
In the supramolecular assembly of complex 2 , the halogen bonding is established between the $\mathrm{Cl}$ atom and one $\mathrm{O}$ atom of the $\mathrm{VO}_{2}{ }^{+}$moiety, which is a better electron donor compared to the $\pi$-system. A dimer, retrieved from the infinite chain, has been computed and the formation energy is similar to that computed for complex $1\left(\Delta E_{2}=-4.6 \mathrm{kcal} \mathrm{mol}^{-1}\right)$, which is likely due to a compensating effect (worse $\sigma$-hole donor and better $\sigma$ hole acceptor compared to complex 1). Complex 3 has a chlorine atom in the ligand part; however, it does not participate in halogen bonding interactions. Instead, it establishes several C$\mathrm{H} \cdots \mathrm{Cl}$ interactions. In fact, its solid state structure shows that each dinuclear complex establishes four sets of $\mathrm{C}-\mathrm{H} \cdots \mathrm{Cl}$ interactions: two as donor and two as acceptors, generating a two dimensional sheet. The interaction energy of the hydrogen bonded dimer is modest, $\Delta E_{3}=-3.7 \mathrm{kcal} \mathrm{mol}^{-1}$ and smaller than the halogen bonding computed for $\mathbf{1}$ and 2 , thus suggesting that the halogen bond is favoured in these vanadium systems. All these results were further corroborated with the molecular electrostatic potential (MEP) surface calculation and NCI plot index computational tool.

\section{Conflicts of interest}

There are no conflicts of interest to declare.

\section{Acknowledgements}

S. T. thanks the DST, India, for awarding a Junior Research Fellowship (IF160359). A. Frontera and A. Franconetti gratefully acknowledge the financial support of this work by the MINECO of Spain (project CTQ2017-85821-R, FEDER funds). In addition, AF thanks the MINECO/AEI from Spain for a "Juan de la Cierva" contract. They thank the CTI (UIB) for free allocation of computer time. M. G. B. D. thanks the University of Reading and the EPSRC (U. K.) for funds for the diffractometer.

\section{Notes and references}

1 (a) J. P. M. Lommerse, A. J. Stone, R. Taylor and F. H. Allen, J. Am. Chem. Soc., 1996, 118, 3108-3116; (b) P. Politzer, P. Lane, M. C. Concha, Y. Ma and J. S. Murray, J. Mol. Model., 2007, 13, 305-311; (c) P. Metrangolo, F. Meyer, T. Pilati, G. Resnati and G. Terraneo, Angew. Chem., Int. Ed., 2008, 47, 6114-6127; (d) P. Politzer, J. S. Murray and M. C. Concha, J. Mol. Model., 2007, 13, 643-650; (e) P. Politzer, J. S. Murray and T. Clark, Phys. Chem. Chem. Phys., 2010, 12, 7748-7757.

2 (a) A. Farina, S. V. Meille, M. T. Messina, P. Metrangolo, G. Resnati and G. Vecchio, Angew. Chem., Int. Ed., 1999, 38, 2433-2436; (b) T. Caronna, R. Liantonio, T. A. Logothetis, P. Metrangolo, T. Pilati and G. Resnati, J. Am. Chem. Soc., 2004, 126, 4500-4501.

3 (a) M. T. Messina, P. Metrangolo, W. Panzeri, E. Ragg and G. Resnati, Tetrahedron Lett., 1998, 39, 9069-9072; (b) H. L. Nguyen, P. N. Horton, M. B. Hursthouse, A. C. Legon and D. W. Bruce, J. Am. Chem. Soc., 2004, 126, 16-17.

4 (a) O. Dumele, B. Schreib, U. Warzok, N. Trapp, C. A. Schalley and F. Diederich, Angew. Chem., Int. Ed., 2017, 56, 1152-
1157; (b) A. C. Legon, Angew. Chem., 1999, 111, 2850-2880; (c) A. C. Legon, Chem.-Eur. J., 1998, 4, 1890-1897.

5 (a) A. M. Maharramova, N. Q. Shikhaliyeva, G. T. Suleymanovaa, A. V. Gurbanova, G. V. Babayevaa, G. Z. Mammadovaa, F. I. Zubkovc, V. G. Nenajdenkod, K. T. Mahmudov and A. J. L. Pombeiro, Dyes Pigm., 2018, 159, 135-141; (b) D. Franchinia, F. Dapiaggia, S. Pieraccinia, A. Fornib and M. Sironi, Chem. Phys. Lett., 2018, 712, 89-94; (c) J. M. Guevara-Vela, D. OchoaResendiz, A. Costales, R. Hernández-Lamoneda and A. M. Pendás, ChemPhysChem, 2018, 19, 2512-2517.

6 (a) L. Brunsveld, J. A. J. M. Vekemans, J. H. K. K. Hirschberg, R. P. Sijbesma and E. W. Meijer, Proc. Natl. Acad. Sci. U. S. A., 2002, 99, 4977-4982; (b) C. M. A. Leenders, L. Albertazzi, T. Mes, M. M. E. Koenigs, A. R. A. Palmans and E. W. Meijer, Chem. Commun., 2013, 49, 1963-1965; (c) M. Henry, ChemPhysChem, 2002, 3, 607-616; (d) C. Schmuck and W. Wienand, Angew. Chem., Int. Ed., 2001, 40, 4363-4369; (e) F. Wang, M. A. J. Gillissen, P. J. M. Stals, A. R. A. Palmans and E. W. Meijer, Chem.-Eur. J., 2012, 18, 11761-11770; (f) T. Kato, N. Mizoshita and K. Kanie, Macromol. Rapid Commun., 2001, 22, 797-814; $(g)$ C. M. Paleos and D. Tsiourvas, Liq. Cryst., 2001, 28, 11271161; (h) F. C. Gozzo, L. S. Santos, R. Augusti, C. S. Consorti, J. Dupont and M. N. Eberlin, Chem.-Eur. J., 2004, 10, 6187-6193.

7 (a) P. Metrangolo and G. Resnati, Chem.-Eur. J., 2001, 7, 2511-2519; (b) E. Corradi, S. V. Meille, M. T. Messina and G. Resnati, Angew. Chem., Int. Ed., 2000, 39, 1782-1786; (c) C. B. Aakeröy, M. Fasulo, N. Schultheiss, J. Desper and C. Moore, J. Am. Chem. Soc., 2007, 129, 13772-13773; (d) G. C. Cole, A. C. Legon and P. Ottaviani, J. Chem. Phys., 2002, 117, 2790.

8 (a) S. Thakur, S. Roy, A. Bauzá, A. Frontera and S. Chattopadhyay, Inorg. Chim. Acta, 2017, 467, 212-220; (b) S. Thakur, N. Sarkar, M. G. B. Drew, A. Bauzá, A. Frontera and S. Chattopadhyay, Polyhedron, 2018, 142, 83-92.

9 (a) G. M. Sheldrick, Acta Crystallogr., Sect. A: Found. Crystallogr., 2008, 64, 112-122; (b) G. M. Sheldrick, Acta Crystallogr., Sect. C: Struct. Chem., 2015, 71, 3-8.

10 A. L. Spek, Acta Crystallogr., 2009, D65, 148-155.

11 J. L. Farrugia, J. Appl. Crystallogr., 2012, 45, 849-854.

12 M. N. Burnett and C. K. Johnson, ORTEP-3: Oak Ridge Thermal Ellipsoid Plot Program for Crystal Structure Illustrations, Report ORNL-6895, Oak Ridge National Laboratory, Oak Ridge, TN, USA, 1996.

13 C. F. Macrae, I. J. Bruno, J. A. Chisholm, P. R. Edgington, P. McCabe, E. Pidcock, L. R. Monge, R. Taylor, J. V. D. Streek and P. A. Wood, J. Appl. Crystallogr., 2008, 41, 466-470.

14 M. J. Frisch, G. W. Trucks, H. B. Schlegel, G. E. Scuseria, M. A. Robb, J. R. Cheeseman, G. Scalmani, V. Barone, B. Mennucci, G. A. Petersson, H. Nakatsuji, M. Caricato, X. Li, H. P. Hratchian, A. F. Izmaylov, J. Bloino, G. Zheng, J. L. Sonnenberg, M. Hada, M. Ehara, K. Toyota, R. Fukuda, J. Hasegawa, M. Ishida, T. Nakajima, Y. Honda, O. Kitao, H. Nakai, T. Vreven, J. A. Montgomery Jr, 
J. E. Peralta, F. Ogliaro, M. Bearpark, J. J. Heyd, E. Brothers, K. N. Kudin, V. N. Staroverov, R. Kobayashi, J. Normand, K. Raghavachari, A. Rendell, J. C. Burant, S. S. Iyengar, J. Tomasi, M. Cossi, N. Rega, J. M. Millam, M. Klene, J. E. Knox, J. B. Cross, V. Bakken, C. Adamo, J. Jaramillo, R. Gomperts, R. E. Stratmann, O. Yazyev, A. J. Austin, R. Cammi, C. Pomelli, J. W. Ochterski, R. L. Martin, K. Morokuma, V. G. Zakrzewski, G. A. Voth, P. Salvador, J. J. Dannenberg, S. Dapprich, A. D. Daniels, Ö. Farkas, J. B. Foresman, J. V. Ortiz, J. Cioslowski and D. J. Fox, Gaussian 09, Gaussian, Inc., Wallingford CT, 2009.

15 S. Grimme, J. Antony, S. Ehrlich and H. Krieg, J. Chem. Phys., 2010, 132, 154104.

16 S. F. Boys and F. Bernardi, Mol. Phys., 1970, 19, 553-566.

17 J. Contreras-García, E. R. Johnson, S. Keinan, R. Chaudret, J.-P. Piquemal, D. N. Beratan and W. Yang, J. Chem. Theory Comput., 2011, 7, 625-632.

18 B. Jeziorski, R. Moszynski and K. Szalewicz, Chem. Rev., 1994, 94, 1887-1930.

19 MOLPRO, A package of ab initio programs, version 2010.1; Molpro, Cardiff, U.K., 2010.

20 (a) L. Sacconi and I. Bertini, Inorg. Chem., 1966, 5, 15201522; (b) M. S. Shongwe, U. A. Al-Zaabi, F. Al-Mjeni, C. S. Eribal, E. Sinn, I. A. Al-Omari, H. H. Hamdeh, D. Matoga, H. Adams, M. J. Morris, A. L. Rheingold, E. Bill and D. J. Sellmyer, Inorg. Chem., 2012, 51, 8241-8253; (c) Y.-Q. Cui, Z.-L. You, X.-F. Li, X.-L. Wang, Y.-P. Ma, C. Wang and C.-L. Zhang, Transition Met. Chem., 2010, 35, 159-163.

21 A. W. Addison, T. N. Rao, J. Reedijk, J. V. Rijn and G. C. Verschoor, J. Chem. Soc., Dalton Trans., 1984, 1349.

22 C. R. Cornman, K. M. Geiser-Bush, S. P. Rowley and P. D. Boyle, Inorg. Chem., 1997, 36, 6401-6408.

23 G. Asgedom, A. Sreedhara, J. Kivikoski, E. Kolehmainen and C. P. Rao, J. Chem. Soc., Dalton Trans., 1996, 93-97.

24 (a) L. M. Mokry and C. J. Carrano, Inorg. Chem., 1993, 32, 6119-6121; (b) E. Kwiatkowski, G. Romanowski, W. Nowicki, M. Kwiatkowski and K. Suwińska, Polyhedron, 2003, 22, 1009-1018.

25 (a) G. Romanowski, E. Kwiatkowski, W. Nowicki, M. Kwiatkowski and T. Lis, Polyhedron, 2008, 27, 16011609; (b) A. Sarkar and S. Pal, Polyhedron, 2007, 26, 12051210.

26 (a) C. A. Duncan, E. P. Copeland, I. A. Kahwa, A. Quick and D. J. Williams, J. Chem. Soc., Dalton Trans., 1997, 6, 917-
919; (b) S. Mondal, M. Mukherjee, K. Dhara, S. Ghosh, J. Ratha, P. Banerjee and A. K. Mukherjee, Cryst. Growth Des., 2007, 7, 1716-1721.

27 Z.-L. You, D.-H. Shi, J.-C. Zhang, Y.-P. Maa, C. Wang and K. Li, Inorg. Chim. Acta, 2012, 384, 54-61.

28 (a) C. A. Root, J. D. Hoeschele, C. R. Cornman, J. W. Kampf and V. L. Pecoraro, Inorg. Chem., 1993, 32, 3855-3861; (b) S. Pal and S. Pal, J. Chem. Crystallogr., 2000, 30, 329-333.

29 (a) Y. Zhang, R. C. Haushalter and J. Zubieta, Inorg. Chim. Acta, 1997, 260, 105-110; (b) W. Plass, Angew. Chem., Int. Ed. Engl., 1996, 35, 627-631.

30 (a) R. Codd, T. W. Hambley and P. A. Lay, Inorg. Chem., 1995, 34, 877-882; (b) H. H. Thorp, Inorg. Chem., 1992, 31, 15851588.

31 (a) P. Bhowmik, S. Chattopadhyay, M. G. B. Drew, C. Diaz and A. Ghosh, Polyhedron, 2010, 29, 2637-2642; (b) P. Bhowmik, H. P. Nayek, M. Corbella, N. Aliaga-Alcalde and S. Chattopadhyay, Dalton Trans., 2011, 40, 7916-7926; (c) F. H. Suydam, Anal. Chem., 1963, 35, 193-195; (d) S. Chattopadhyay, M. S. Ray, S. Chaudhuri, G. Mukhopadhyay, G. Bocelli, A. Cantoni and A. Ghosh, Inorg. Chim. Acta, 2006, 359, 1367-1375.

32 (a) M. R. Maurya, A. Kumar, M. Abid and A. Azam, Inorg. Chim. Acta, 2006, 359, 2439-2447; (b) E. Kwiatkowski, G. Romanowski, W. Nowicki, M. Kwiatkowski and K. Suwińska, Polyhedron, 2007, 26, 2559-2568.

33 X. Wang, X. M. Zhang and H. X. Liu, Inorg. Chim. Acta, 1994, 223, 193-197.

34 (a) S. Rayati, N. Sadeghzadeh and H. R. Khavasi, Inorg. Chem. Commun., 2007, 10, 1545-1548; (b) G. F. Svatos, C. Curran and J. V. Quagliano, J. Am. Chem. Soc., 1955, 77, 6159-6163.

35 G. Grivani, A. D. Khalaji, V. Tahmasebi, K. Gotoh and H. Ishida, Polyhedron, 2012, 31, 265-271.

36 (a) R. Dinda, P. Sengupta, S. Ghosh and T. C. W. Mak, Inorg. Chem., 2002, 41, 1684-1688; (b) G. Asgedom, A. Sreedhara, J. Kivikoski, E. Kolehmainen and C. P. Rao, J. Chem. Soc., Dalton Trans., 1996, 93-97.

37 M. R. Maurya, A. Kumar, A. R. Bhat, A. Azam, C. Bader and D. Rehder, Inorg. Chem., 2006, 45, 1260-1269.

38 (a) J. Dai, S. Akiyama, M. Munakata and M. Mikuriya, Polyhedron, 1994, 13, 2495-2499; (b) T. Ghosh, B. Mondal, T. Ghosh, M. Sutradhar, G. Mukherjee and M. G. B. Drew, Inorg. Chim. Acta, 2007, 360, 1753-1761. 